\title{
How to Diagnose Hidden Caries? The Role of Laser Fluorescence
}

\author{
Camilo Abalos, Amparo Jiménez-Planas, \\ Elena Guerrero, Manuela Herrera and Rafael Llamas \\ University of Seville, School Dentistry, \\ Spain
}

\section{Introduction}

The diagnosis of pits, grooves and fissures is one of the main challenges facing dentists in their professional activity, since the existence of an intact enamel surface may hide deep caries in dentin. Lesions of this kind were described by Weerheijm et al. (1992) as "hidden caries". Over 70 years ago a high incidence of caries was confirmed in grooves and fissures (Hyat, 1923), in coincidence with more recent observations (Bragamian \& Garcia-Godoy, 2009). In order to understand and explain this high incidence and the morphological peculiarities involved, it is essential to know the physiopathology of the tooth and of the carious lesion.

Caries is a "multifactorial disease causing dissolution of the organic component and demineralization of the inorganic component of the hard dental tissues" (Bonilla, 1998). In the chronology of this process is must be noted that the enamel is a filtering membrane allowing the transit of substances from the exterior to the interior, and vice versa (Llamas et al., 2000). This is because the enamel contains areas with increased water and organic material contents, such as the lamellae or cracks, striae of Retzius, adamantine rod sheath, inter-rod space, and inter-crystalline areas, among others. These zones allow the flow of acids from bacterial plaque, giving rise to disintegration of the organic material and posteriorly conditioning demineralization of the inorganic component - thus supporting the proteolysis - chelation theory of dental caries. These enamel areas with disintegration of the organic material, and the large structural defects such as cracks, which are rich in organic material, can facilitate the penetration of bacteria into deep areas of the enamel, without the existence of superficial cavitation (Brännstrom et al., 1980).

The unpredictable, irregular and varied morphology of the grooves and fissures is well known and makes it impossible to pre-determine the structure; however, it is known that over $50 \%$ of all studied teeth have cracks in the depths of the fissures that facilitate the rapid transit of substances and/or bacteria from the depth of the sulcus to the dentin (Pastor et al., 1998). On furthermore considering that enamel thickness from the depth of the sulcus to the dentin is variable and in some cases inexistent, it can be understood why a carious lesion beginning within a fissure can develop in enamel and even in dentin without any external clinical or morphological signs of caries. This in turn explains how in some cases we can 
observe grooves and fissures that are apparently normal or with a discrete brown or blackish color, but with no cavitations reflecting an incipient or consolidated lesion affecting even the dentin (Fig.1). In view of the above, how can we know if we are dealing with a true initial dentinal carious lesion if the tooth appears to be healthy? Or how can we diagnose something in depth based on the surface appearance? On the other hand, how and when do we decide to open the fissure or not? If we fail to open the fissure dentin caries may exist and progress rapidly; alternatively, a decision to open the fissure may cause us to needlessly damage an intact tooth. We thus face a diagnostic dilemma.

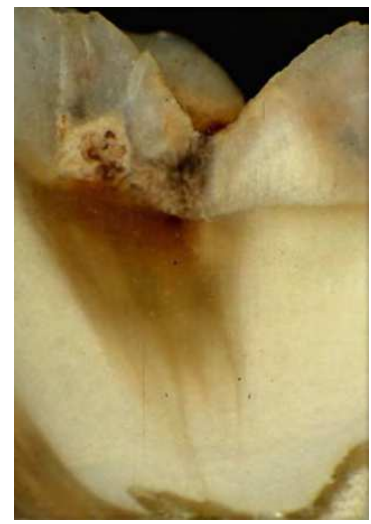

Fig. 1. Non-cavitated occlusal caries with deep dentin involvement.

This problem could be a minor concern if the disorder in question were of low prevalence. However, despite the decrease in the frequency of caries in the industrialized world over the last 20 years (Mejàre et al., 2004), not all clinical forms of caries have evolved equally; indeed, caries of grooves and fissures are those showing the greatest prevalence at the present time, since the most notorious decrease has corresponded to caries of smooth surface (Bagramian \& Garcia-Godoy, 2009). The form of presentation has also changed; in effect, enamel presently takes longer in becoming affected, thanks mainly to continuous exposure to fluor. As a result, caries develops more slowly, with preservation of enamel integrity for longer periods of time. At present, caries of grooves and fissures affect between $10-50 \%$ of the permanent molars of adolescents (Weerheijm et al., 1992), these being the locations where most carious lesions are found, and non-cavitation persists for a longer period of time. Based on the above, it can be concluded that we are not only facing a diagnostic problem, with a high prevalence in adolescents and young adults, but are also facing a buccodental health problem.

The objective of modern Odontology should be to ensure the prevention of caries, avoiding invasive treatments as far as possible. However, this is only possible if full restitution of the affected tissue is achieved (Hibst et al., 2001). In this context, diagnostic tools should evolve in order to allow us to detect the first signs of enamel demineralization. In other words, the tendency should be to facilitate the early detection of caries, with a view to adopting noninvasive treatments and the corresponding preventive measures. On the other hand, we fundamentally should center on common diagnostic techniques that are accessible to dentists, in order for such strategies to be applicable to routine clinical practice. 


\section{Diagnostic tests}

The existing means for the diagnosis of non-cavitary occlusal caries of grooves and fissures are diverse in terms of the underlying principles and diagnostic capacity. The techniques can be classified according to the frequency with which they are used: the most common are visual inspection (VI) and VI with magnification (VIM), the caries probe (CP), conventional $\mathrm{X}$-rays $(\mathrm{Rx})$ and digital $\mathrm{X}$-rays $(\mathrm{RxD})$; less common techniques (though still accessible to clinicians) are fiber-optic transillumination (FOTI and DiFOTI) and laser fluorescence (LF); and finally unusual or experimental techniques are those which presently are not generally used in clinical practice or which are still in the experimental phase - their use being confined to certain research settings. These latter techniques include the measurement of tissue electrical conductance, based on the reduction of electrical resistance or impedance that characterizes caried tissue (Pretty, 2006), using the electronic caries monitorization (ECM), while other methods are based on qualitative light-induced fluorescence (QLF) which uses two types of fluorescence and generates images that can be filed for posterior comparison, with the capacity to determine whether the lesions are active or not. In turn, among the purely experimental techniques, mention should be made of optical coherence tomography (OCT), which generates images in the near-infrared region, and is able to detect incipient enamel caries in vitro (Ngaotheppitak et al., 2005).

\subsection{Visual inspection (VI)}

Visual inspection is the most widely used diagnostic method. VI has a long history, but is subjective and depends on the experience of the examiner (Pretty, 2006; Zandona \& Zero, 2006). The diagnosis of a cavitated lesion poses no diagnostic difficulty of any kind; it is in the case of the so-called "hidden caries" where doubts arise, together with the impossibility of determining whether a dark fissure presents underlying caries or merely corresponds to surface staining. In their first stages, caries of grooves, pits and fissures appear as a milky or darkish stain indicating demineralization of the walls of the fissure and implying enamel opacity. In addition, there may be decoloration of the dentin through the enamel, as well as defects in the bottom or depth of the pit, which would confirm the diagnosis of dentin caries. Accordingly, clinical inspection is based on evaluation of the transparency changes of the enamel, loss of brightness, an opaque appearance, and integrity of the fissure (Thylstrup et al., 1994; Ekstrand et al., 1997). In order to appreciate these changes, the occlusal surfaces must be clean and dry during inspection of the grooves and fissures. Drying the enamel reduces the refraction index of the inter-rod spaces (from 1.33 in the case of humid or moist demineralized surfaces to 1.0 in the case of dry demineralized surfaces) - this making it possible to easily visualize the opaque appearance of enamel demineralization caused by the bacterial plaque acids (Kidd et al., 1993). We can also evaluate pigmentations, the presence or absence of soft tissues, or changes in enamel texture according to the degree of demineralization. According to some authors (Thylstrup et al., 1994), we are also able to establish whether the caries are active or inactive. The evaluation of these findings must be made following some classifying method or criterion capable of correlating the observed signs to the stage of the lesion. The system developed from the studies of Thylstrup in 1994 (Thylstrup et al., 1994) and posteriorly structured by Ekstrand in 1997 (Ekstrand et al., 1997) and modified in 1998 (Ekstrand et al., 1998) is one of the most widely used options. The criteria established by Ekstrand et al. (1997) are the following: $0=$ no or slight change in enamel translucency after prolonged air drying; 1 = opacity or discoloration hardly visible 
on the wet surface, but distinctly visible after air drying; 2 = opacity or discoloration distinctly visible without air drying; 3 = localized enamel breakdown in opaque or discolored enamel and/or grayish discoloration from underlying dentin; and $4=$ cavitation in opaque or discolored enamel exposing the dentin (Fig. 2). Other criteria have also been developed, however, such as those of Nyvad (Nyvad et al., 1999), the ICDAS (International Caries Detection and Assessment System (Pitts, 2004), the UniViSS (Universal Visual Scoring System for Caries Detection and Diagnosis) (Kuhnisch et al., 2009), or even the International Consensus Workshop on Caries Clinical Trials (ICW-CCT), where caries activity and inactivity are taken into consideration (Pitts \& Stamm, 2004).
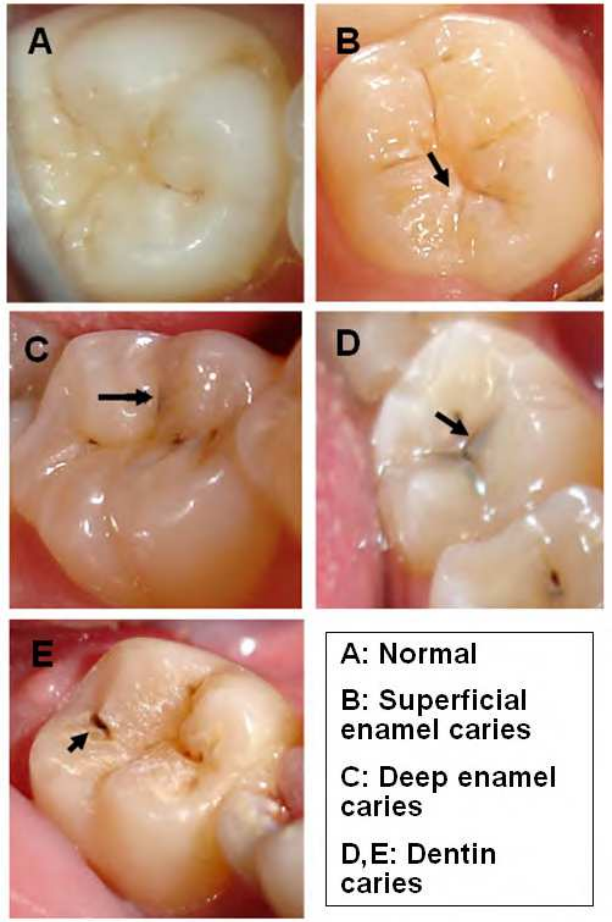

Fig. 2. Representative signs of caries in cracks and fissures, according to the Ekstrand criteria.

The sensitivity of visual inspection varies greatly depending on the literature source. Our review of the existing publications yielded values between 0.12 and 0.97 . A sensitivity of 0.62 to 0.90 is common when there are visible cavities in the fissures. However, in hidden dentin caries, different studies (Lussi, 1993; Wenzel et al., 1991) have reported sensitivity values as low as 0.12 . This low sensitivity is due to the fact that we cannot inspect beneath an apparently healthy enamel layer. Some authors (Ekstrand et al., 1997; Pereira et al., 2001) have obtained high sensitivity values that may be justified in part by elimination of a portion of the study sample due to validation problems or because of the presence of stained fissures. Application of the Ekstrand criteria tends to increase the sensitivity of the test both in vitro (Ekstrand et al., 1997; Tranæus et al., 2005) and in vivo (Angnes et al., 2005; Reis et al., 
2006). Some studies do not draw these conclusions, however (Heinrich-Weltzien et al., 2002). In effect, Lussi (Lussi et al., 2001) reported that visual inspection alone does not offer good sensitivity in detecting occlusal dentin caries. The width of the fissure also influences sensitivity; in this sense, a diagnosis is more difficult to establish in the presence of narrow fissures than in the case of wide fissures (Lussi, 1991). In vivo studies pose the inconvenience of incomplete sample validation, or the use of samples comprising third molars or premolars, with anatomical features different from those of the permanent first and second molars. Most studies indicate that visual inspection offers low-medium sensitivity and high specificity in the diagnosis of occlusal non-cavitated caries (Kidd et al., 1993; Wenzel et al., 1991; Reis et al., 2006; Heinrich-Weltzien et al., 2002) (Table 1).

\begin{tabular}{|c|c|c|c|c|}
\hline AUTHOR & LEVEL & STUDY & SENSITIVITY & SPECIFICITY \\
\hline Lussi 1993 & dentin & in vitro & 0.12 & 0.93 \\
\hline Ektrand 1997 & dentin & in vitro & $0.92-0.97$ & $0.85-0.93$ \\
\hline Reis 2006 & dentin & in vitro & 0.69 & 0.88 \\
\hline Ashley 1998 & enamel & in vivo & 0.60 & 0.73 \\
\hline Angnes 2005 & dentin & in vivo & $0.75 / 0.68$ & $0.84 / 0.81$ \\
\hline
\end{tabular}

Table 1. Sensitivity and specificity values for visual inspection.

In our studies (Abalos et al., 2009, 2011; Guerrero, 2011) of laser fluorescence, we obtained a sensitivity for visual inspection of over 0.70 , in application to both enamel caries and dentin caries. In contrast to other authors, we achieved total validation of the sample of first and second molars in vivo, since we used teeth that were to be prepared for fixed prostheses. This afforded more realistic sensitivity and specificity values for the studied tests. However, in the case of VI, we consider that our results exceed those obtainable in the real life scenario, since as has been explained in our studies (Abalos et al., 2009, 2011; Guerrero, 2011), in our selection of the sample we aimed to secure a sufficient proportion of teeth that were clearly healthy or with enamel caries - a fact that may have influenced the recorded high sensitivity for VI. However, when using the criteria of Ekstrand (Ekstrand et al., 1997), with drying of the tooth (Tranæus et al., 2005; Ekstrand et al., 1997; Angnes et al., 2005; Reis et al., 2006), the sensitivity of the test increases. Many studies of VI have been published, and the results differ greatly according to the type of methodology used (Bader \& Shugars, 2004). Despite this fact, VI is a technique that will continue to be used in routine clinical practice. However, rather than focusing on the true diagnostic performance of VI, which is clearly influenced by the examiner and the inaccessible depth of the fissures, future research should attempt to establish which tests are really useful, and to what extent, as coadjutants to visual inspection.

The mentioned moderate sensitivity is accompanied by high specificity (Table 1). In other words, while we must accept the probability of false-negative findings (Costa et al., 2008), the high specificity of the test and its important positive predictive value (PPV) (Guerrero, 2011) point to the advisability of opening all fissures with scores of 3 or 4 on the Ekstrand scale (Fig.2D,E). This is where the true usefulness of the test is found: when signs of caries are identified, caries may very well be present.

Regarding the reproducibility of the test, the studies that determine inter-examiner agreement or concordance (Lussi, 1991; Anttonen et al., 2003; Costa et al., 2008) report kappa 
(k) values of $>0.61$ to $>0.81$. The reported intra-examiner reproducibility (Lussi, 1991; Anttonen et al., 2003; Costa et al., 2008) in turn yields $\mathrm{k}$ values of $>0.41$ to $>0.81$. This scale was developed by Landis and Koch (Landis \& Koch, 1977), who scored the concordance values for the $\mathrm{k}$ index from $<0$ (no concordance) to 0-0.20 (insignificant or slight concordance), $0.21-0.40$ (discrete concordance), $0.41-0.60$ (moderate concordance), $0.61-0.80$ (substantial concordance) and 0.81-1 (near-perfect concordance).

In sum, it is important for dentists to become familiarized with this exploration modality, without being too conditioned by superficially stained fissures that do not meet the specified criteria and which can lead to over-treatment. The prevalence of caries and the potential patient risk are important aspects that must be taken into account. A low caries prevalence with good molar hygiene and no bacterial plaque improve the reliability of the test, since there is a lesser probability of establishing an incorrect diagnosis. Visual inspection is the first method to be used in application to hidden dentin caries. In the case of a positive diagnosis, we should open the fissure and use a probe to explore the hardness of the dentin (Kidd et al., 1996). However, a negative diagnosis does not rule out the existence of caries, and other tests must be used together with VI in such situations - particularly in the presence of stained fissures.

\subsection{Visual inspection with magnification (VIM)}

Visual inspection with magnification (VIM) involves all the criteria and arguments defined for visual inspection (VI) without magnification. In the same way as with VI, the reported sensitivity data differ greatly, and can be as low as 0.20 (Lussi, 1993) - though accompanied by high specificity in most studies (Lussi, 1991). Magnification can improve the diagnostic performance of the test (Ekstrand et al., 1998; Lussi \& Francescut, 2003). In this context, different studies have compared both methods (Lussi, 1993; Lussi, 1991; Lussi \& Francescut, 2003), with the observation of superior sensitivity and specificity for VIM, though without reaching statistically significant differences versus VI. We obtained similar results, with a sensitivity rating for VIM (x2.6 magnification) of 0.76, versus 0.71 for VI (Guerrero, 2011). Our observed specificity (Guerrero, 2011) in turn is high, with a value of 0.84 . In line with these results, Lussi (Lussi \& Francescut, 2003) reported moderate sensitivity (0.65) and high specificity (0.96). Figure 3 simulates the view we would have of the occlusal surface of a lower second premolar without magnification (i.e., real size) and under $\times 3.5$ magnification. We can see that visual examination is easier with VIM; thus, although the literature reports no significant differences in performance between the two techniques, VIM is the preferred option, since it allows better appreciation of the possible signs of caries.

The importance of VI and VIM is attributable to their positive predictive value (PPV), which exceeds $90 \%$ (Guerrero 2011). In other words, when a positive diagnosis is established, caries is almost sure to be present. The same cannot be said of a negative diagnosis, however, since the negative predictive value (NPV) of the test is not so high. Therefore, we are unable to rule out the possibility of a false-negative diagnosis, since with this test it is often impossible to examine the depths of the fissures. In this sense, according to Lundberg (Lundberg et al., 2007), in the permanent first molars we observe a relationship between pit depth and bacterial colonization. Specifically, central pits are deeper and more varied in their morphology than less deeper mesial pits. There is an interesting correlation between central pits and colonization by Streptococcus mutans, and trapped organic material moreover may 
contribute to a faster evolution of hidden caries (Lundberg et al., 2007). In this sense, despite the use of magnification, visual inspection is far from being able to detect these etiopathogenic factors. In this sense, the visual diagnostic techniques require improvement or combination with other diagnostic methods in order to detect these early or incipient stages of caries. In conclusion, and in agreement with the studies of Forgie (Forgie et al., 2002) regarding the use of magnification in relation to other diagnostic techniques, VIM is the method of choice for the detection of occlusal non-cavitated caries, despite the limitations commented above.
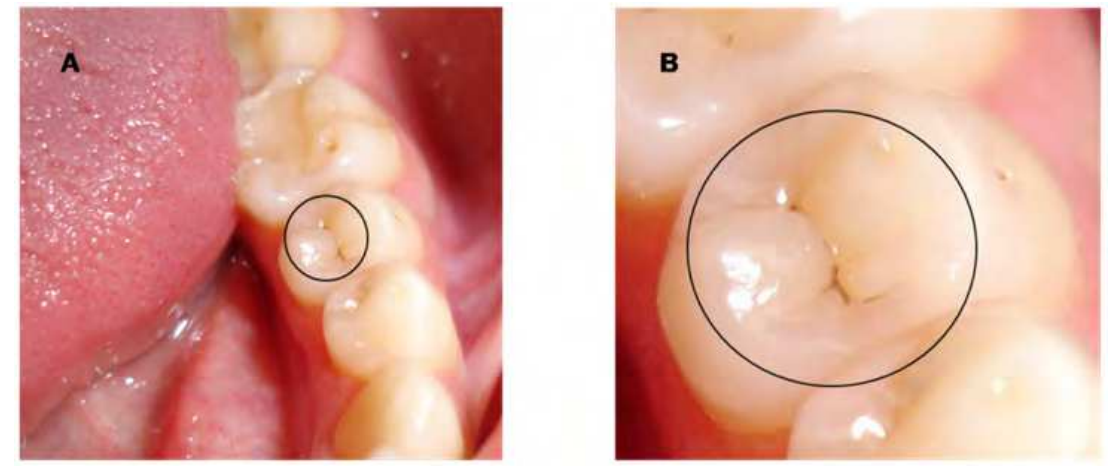

Fig. 3. Visual inspection of the occlusal surface of a second premolar (A: real size, and B:under x3.5 magnification).

\subsection{Caries probing (CP) or tactile examination}

Until recently, probe exploration formed part of the diagnostic routine in occlusal caries. Probe entrapment in the grooves and fissures helped in establishing the diagnosis. Although this technique is now contraindicated, some professionals continue to use caries probing (CP). The exploration probe has been evaluated as a diagnostic tool in many studies (Lussi, 1991; Lussi \& Francescut, 2003). The sensitivity of CP in the detection of occlusal caries is 0.5-0.6 (Hamilton, 2005), though with high specificity values (Bader et al., 2002). The tip of the probe is unable to reach the bottom of the fissures, because of its thickness and the anatomy of the fissures. The probe tip size varies depending on the manufacturer. This lack of standardization of the tip size can make exploration difficult (Lussi, 1993). In addition, a number of studies (Lussi, 1991; Hibst et al., 2001; Hamilton, 2005) have demonstrated that a sharp-tipped probe can cause damage to recently erupted teeth and produce a cavity in a demineralized zone. As a result, the use of such instruments has been the subject of debate for years. Likewise, CP can transmit Streptococcus mutans from a contaminated fissure to a healthy fissure (Loesche et al., 1979). On the other hand, CP in combination with visual inspection (VI) does not improve the overall diagnostic performance of the exploration in application to caries of pits and fissures (Lussi, 1991; Lussi, 1993; McComb \& Tam, 2001). Based on the above, the use of a round-tipped probe or periodontal probe alone would be justified for eliminating remnant material within the fissure before VI, and for evaluating the texture of the surface without penetrating the latter (Zandona \& Zero, 2006; Ekstrand et al., 2005; Hamilton, 2005). Other applications would be contraindicated, however. 


\subsection{Conventional X-rays (Rx)}

Clinical inspection is completed by radiological evaluation. Bitewing X-rays represent the technique of choice for diagnosing proximal surface caries, though they may also be useful for diagnosing occlusal dentin caries (Tranæus et al., 2005; Wenzel et al., 1992). At occlusal level, the X-rays register a tooth thickness beyond the proximal zone, and the lesions are masked by the healthy tissues for a longer period of time (Wenzel et al., 1992). For this reason, from the histological perspective, the lesion is more advanced than suggested by its radiological appearance - a fact that justifies the low sensitivity of the technique. In our studies, the observed sensitivity was 0.57 (Guerrero, 2011), i.e., many existing lesions are not detected. Nevertheless, once again, the specificity is very high. These results imply that negative $\mathrm{X}$-ray findings cannot be taken to rule out dentin caries, though a positive X-ray diagnosis should be taken as an indication for opening the fissure and providing caries treatment. The reviewed in vivo and in vitro studies (Wenzel et al., 1992, Lussi, 1993; Angnes et al., 2005; Lussi et al., 2001; Ashley et al., 1998; Costa et al., 2008) point to low sensitivity and high specificity, in coincidence with our own results (Table 2). Only studies involving third molars report lesser specificity, possibly due to the difficulty of correctly obtaining Xray projections in this zone.

\begin{tabular}{|c|c|c|c|c|}
\hline AUTHOR & LEVEL & STUDY & SENSITIVITY & SPECIFICITY \\
\hline Ashley 1998 & enamel & in vitro & 0.19 & 0.80 \\
\hline Wenzel 1990 & enamel & in vitro & 0.44 & 0.70 \\
\hline Ricketts 1997 & dentin & in vitro & 0.14 & 0.95 \\
\hline Ashley 1998 & dentin & in vitro & 0.24 & 0.89 \\
\hline Wenzel 1992 & dentin & in vitro & 0.48 & 0.81 \\
\hline Lussi 2001 & dentin & in vivo & 0.63 & 0.99 \\
\hline Heinrich 2002 & dentin & in vivo & 0.70 & 0.96 \\
\hline Angnes 2005 & dentin & in vivo & $0.0-0.06$ & $0.98-0.96$ \\
\hline Costa 2008 & dentin & in vivo & 0.26 & 0.94 \\
\hline
\end{tabular}

Table 2. Sensitivity and specificity values for the X-ray diagnostic evaluation of occlusal caries.

The main difficulty of conventional X-ray exploration is the distinction between deep enamel and superficial dentin, due to superpositioning of the healthy vestibular and lingual enamel, which masks the radiotransparency, particularly in early-stage lesions. Carious lesions normally cannot be detected on X-rays until they have extended about $0.5 \mathrm{~mm}$ beyond the amelodentinal junction (Kidd et al., 1993). Even with this difficulty, however, in vitro studies point to acceptable correlation with the existing histological condition. In this context, Wenzel (Wenzel, 1998) suggested that the in vitro diagnostic performance may be better than in the actual clinical setting, i.e., the results obtained in the laboratory may be overestimated. However, other in vitro studies indicate that by the time occlusal caries have been identified on the X-rays, demineralization has already extended to the middle third of the dentinal layer, i.e., the deep dentin (Ricketts et al., 1997). Weerheijm (Weerheijm et al., 1992) reported that X-rays are not very effective for diagnosing incipient enamel caries, though the technique is very useful for diagnosing deeper lesions. In this context, conventional X-rays improve the diagnostic capacity of VI by $11 \%$, and moreover help assess the extent of the lesion (Ekstrand et al., 1995). 
Regarding the predictive value of the technique, our group (Guerrero, 2011) has recorded a PPV of $100 \%$, suggesting that a positive diagnosis implies the existence of caries, since falsepositive interpretations are very unlikely. In turn, we recorded a NPV of 59\%, i.e., normal Xray findings do not discard the possibility that an occlusal lesion may have invaded dentin. In relation to the inter-examiner reproducibility of the technique, the results are varied and range from kappa index $(\mathrm{k})$ values of 0.39 (weak concordance) to 0.95 (near-perfect concordance) (Angnes et al., 2005; Costa et al., 2008; Cortes et al., 2000) - though most studies report substantial concordance values (0.61-0.80).

In sum, bitewing X-rays are an obligate diagnostic tool for proximal surface caries and represent a good adjunct in the diagnosis of occlusal caries. Considering that VI results in an important percentage of undetected clinical lesions (Wolwacz et al., 2004), particularly in adolescents (Wenzel et al., 1992), the bitewing X-rays must be carefully evaluated for possible lesions beneath the occlusal enamel. Figure 4 shows caries in dentin with a noncavitated occlusal surface. However, a normal X-ray study does not rule out the presence of hidden dentin caries, in view of the low sensitivity and NPV of the technique.
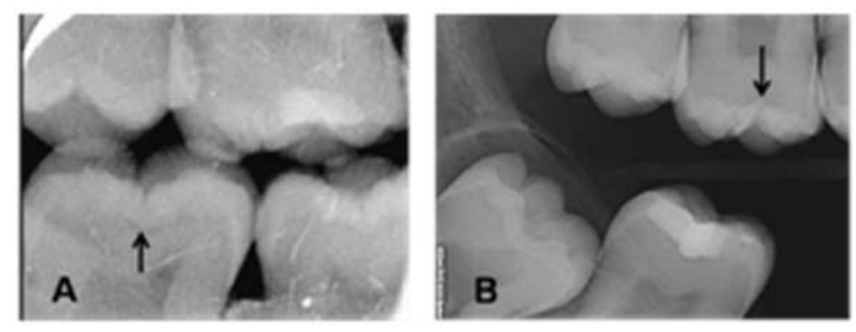

Fig. 4. Hidden dentin caries diagnosed from bitewing X-rays (A: dentin caries, B: early dentin caries)

\subsection{Digital X-rays (RxD)}

The application of digital X-rays (RxD) has gradually increased in dental practice, and the number of professionals who incorporate this technology to their personal practices is on the rise. RxD offer a number of advantages: the image is obtained immediately, with no need for development; the patient is exposed to a lesser radiation dose; and the images are examined using software that moreover allows them to be filed in electronic format, offering different forms of presentation and image measurements (Fig. 5).

In the same way as conventional $\mathrm{X}$-rays, $\mathrm{RxD}$ offers low sensitivity and high specificity. We have recorded a sensitivity of 0.61 and a specificity of 0.96 , i.e., practically without differences with respect to the conventional X-ray technique. The comparisons of these results with those found in the literature confirm the high specificity and limited sensitivity, though the reported sensitivity range is 0.30-0.70, versus 0.70-0.95 in the case of specificity (Table 3).

Regarding the comparison of both radiological techniques, some authors (Wenzel et al., 1992) consider that there are no differences between conventional X-rays and digital X-rays, in concordance with our own results. In contrast, other studies (Pretty, 2006; Lussi, 1993) have reported slightly greater sensitivity with $\mathrm{RxD}$, and some investigators (McComb \& Tam, 2001) consider that this technique improves diagnostic performance in early-stage 
caries. Further studies involving larger sample sizes are needed to confirm whether RxD improves diagnostic performance with respect to conventional X-rays. Similar considerations apply to VIM versus VI: it makes our work easier, diagnostic performance seems to be better, but analysis of the results fails to reveal statistically significant differences - the latter being taken to represent a difference of over 0.1 in sensitivity/specificity or a difference of over $10 \%$ in PPV/NPV.
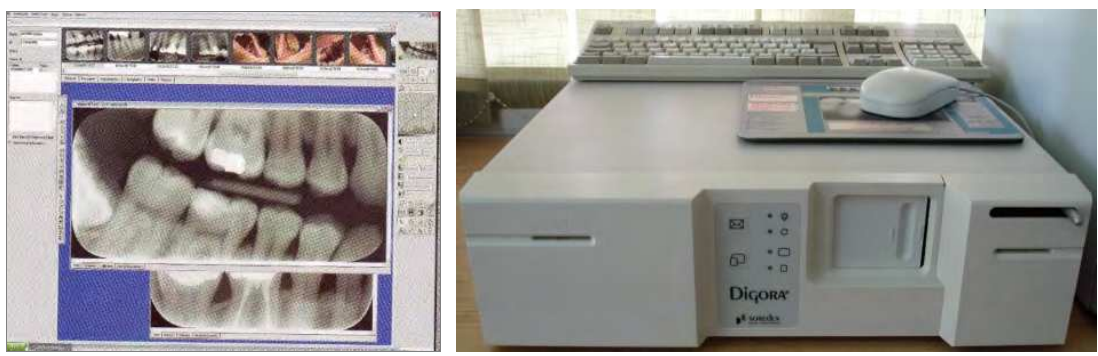

Fig. 5. Digital X-rays system (Digora Trophy Elitys)

\begin{tabular}{|c|c|c|c|c|}
\hline AUTHOR & LEVEL & STUDY & SENSITIVITY & SPECIFICITY \\
\hline Wenzel 1990 & enamel & in vitro & 0.31 & 0.72 \\
\hline Wenzel 1992 & dentin & in vitro & 0.71 & 0.85 \\
\hline Huysmans 1998 & dentin & in vitro & $0.52-0.60$ & $0.91-0.95$ \\
\hline Ashley 1998 & dentin & in vitro & 0.19 & 0.89 \\
\hline Wenzel 2008 & dentin & in vitro & 0.31 & 0.93 \\
\hline
\end{tabular}

Table 3. Sensitivity and specificity values for the digital X-rays diagnostic evaluation of occlusal caries.

Regarding the predictive usefulness of the technique, in our study (Guerrero, 2011) the PPV of RxD was found to be $97 \%$, i.e., a positive diagnostic reading implies the almost sure presence of caries. However, the same cannot be said when the diagnosis proves negative (i.e., indicative of a healthy tooth), since the proportion of false-negative results is high (NPV 60\%).

\subsection{Laser fluorescence (LF)}

Laser fluorescence (LF) (Fig. 6) is less widely known and used by dental professionals, though it constitutes a necessary complement to the traditional methods. LF therefore deserves a more detailed description in this Chapter. Fluorescence occurs as a result of the interaction between electromagnetic radiation and tissue molecules. When light falls upon the surface of the tooth it penetrates a few millimeters into the tissue, and is reflected towards the tip of a device that measures the fluorescence by means of an electronic system. Two incremental ranges are observed in the fluorescence spectrum: one at 430-450 nm, related to demineralization of the tooth, and another at 590-650 $\mathrm{nm}$, related to the presence of bacteria and their metabolites (Lundberg et al., 2007). Furthermore, there are other elements of organic and inorganic origin that can emit additional fluorescence and thus lead to error in the detection of caries: fluorosis, hypomineralization, bacterial plaque, calculus, proximal surface caries and other stains. 


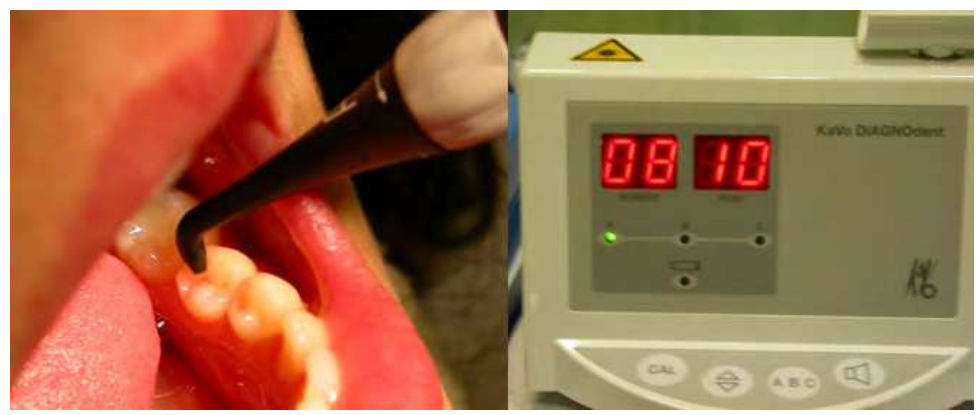

Fig. 6. Laser fluorescence device (DIAGNOdent, KaVo, Biberach, Germany)

The origin of the fluorescence is not fully clear (Pretty \& Maupome, 2004; Tranæus et al., 2005), though it seems unlikely that apatite is responsible for the basal values associated with normal (healthy) enamel (Hibst et al., 2001). The explanation may be the result of the combination of the inorganic matrix with the absorption of organic molecules (Hibst \& Paulus, 1999). During the formation of caries an increase in fluorescence is observed related to two processes: demineralization of the tooth, and bacteria with their metabolic products (porphyrin) (Pretty \& Maupome, 2004; Tranæus et al., 2005). Most of the fluorescence is induced by the organic components (Tranæus et al., 2005; Hibst et al., 2001), rather than by crystal disintegration and transmission through scantly homogeneous enamel (Farah et al., 2008). This hypothesis is based on the fact that LF does not detect lesions caused in the laboratory with acids not produced as a result of bacterial activity (Pretty \& Maupome, 2004). However, LF is able to detect early enamel lesions with a fluorescent stain (porphyrin TMPyP) (Mendes et al., 2006).

The results of the first in vitro studies with LF were promising, with high sensitivity and good reproducibility (Lussi et al., 1999). For dentin caries, many investigations have recorded sensitivity values in a very narrow range close to the highest values on the scale (0.79 - 1.0) (Bader \& Shugars, 2004; Lussi et al., 1999). Few studies (Bader \& Shugars, 2004) have described very low sensitivity ( 0.19 and 0.26$)$ - such findings being attributable to subjectiveness and errors in the measurement technique during rotation of the instrument tip (Bader \& Shugars, 2004; Reis et al., 2006). Although most studies report high sensitivity, the associated specificity is varied. The specificity values of LF in reference to dentin caries in permanent teeth ranges from 0.50 to 1.0 (Lussi et al., 2001; Pretty \& Maupome, 2004; Baseren \& Gokalp, 2003). Several studies (Bamzahim et al., 2002, 2000; Pereira et al., 2001) have reported near-perfect specificity for LF, thanks to the selection of those teeth with the highest LF readings (Bamzahim et al., 2002), while other authors explain the situation in terms of low sensitivity of the technique (Pereira et al., 2001). In the case of enamel caries the results are contradictory, with either moderate sensitivity ratings associated to high specificity values, or high sensitivity with moderate specificity (Table 4). High sensitivity is in agreement with the observations of previous in vivo studies, though without validation based on fissurotomy (Anttonen et al., 2003; Lussi \& Francescut, 2003). The above considerations are also consistent with other studies involving histological validation and measurement of third molars (Reis et al., 2006), and with in vitro investigations involving third molars stored at $-20^{\circ} \mathrm{C}$ (Lussi \& Hellwig, 2006). In our study (Abalos et al., 2011), high 
sensitivity was accompanied by limited specificity (0.63) which, although coinciding with the findings of other authors (Bader \& Shugars, 2004; Reis et al., 2006) is lower than in others studies (Lussi et al., 2000; Bașeren \& Gokalp, 2003; Anttonen et al., 2003; Lussi \& Hellwig, 2006). Low specificity could be partially due to the fact that we did not eliminate teeth with the presence of brown or dark spots on fissures from the study sample. This low specificity at $\mathrm{D}_{1}$ level (healthy/enamel caries) is less important than at $\mathrm{D}_{3}$ level (enamel caries/dentin caries), where the proportion of false-positive readings can have negative consequences, since it can lead to over-treatment. Table 4 summarizes the results of some representative studies in relation to sensitivity and specificity, though for reasons that will be addressed below, the findings of our investigations (Abalos et al., 2009; 2011) may actually be closest to the true situation.

\begin{tabular}{|c|c|c|c|c|}
\hline AUTHOR & LEVEL & STUDY & SENSITIVITY & SPECIFICITY \\
\hline Lussi 2001 & enamel & in vitro & $0.38-0.95$ & $0.24-0.95$ \\
\hline Stookey 2001 & enamel & in vitro & $0.42-0.87$ & $0.72-0.95$ \\
\hline Abalos 2011 & enamel & in vivo & 0.97 & 0.63 \\
\hline Lussi 1999 & dentin & in vitro & $0.76-0.84$ & $0.79-0.87$ \\
\hline Hibst 2001 & dentin & in vitro & 0.92 & 0.86 \\
\hline Stookey 2001 & dentin & in vitro & $0.76-0.84$ & $0.79-1.00$ \\
\hline Heinrich 2003 & dentin & in vitro & $0.93-0.99$ & $0.13-0.63$ \\
\hline Reis 2006 & dentin & in vitro & $0.71-0.78$ & $0.57-0.63$ \\
\hline Lussi 2001 & dentin & in vivo & 0.92 & 0.86 \\
\hline Agnes 2005 & dentin & in vivo & $0.68-0.81$ & $0.56-0.54$ \\
\hline Reis 2006 & dentin & in vivo & $0.80-0.75$ & $0.43-0.52$ \\
\hline Abalos 2009 & dentin & in vivo & 0.89 & 0.75 \\
\hline
\end{tabular}

Table 4. Sensitivity and specificity of laser fluorescence in the diagnosis of occlusal noncavitated caries.

Most studies evaluating LF have been carried out in vitro (Tranæus et al., 2005; Stookey \& Gonzalez-Cabezas, 2001; Hibst et al., 2001; Bader \& Shugars, 2004; Lussi et al., 1999), though there are also a number of in vivo studies (Anttonen et al., 2003; Angnes et al., 2005; Heinrich-Weltzien et al., 2003; Lussi et al., 2001; Reis et al., 2006; Abalos et al., 2009; Abalos et al., 2011). The results of in vitro studies cannot be extrapolated to in vivo conditions, and the limitations of these studies are know. The way in which the teeth are preserved, or the changes in their organic content after extraction, are the main factors inducing alterations in dental tissue fluorescence. The mentioned organic matrix begins to degrade in the second week of preservation of the tooth. When teeth are preserved in formalin, thymol or chlorine (Francescut et al., 2006), the fluorescence value in the occlusal surface decreases rapidly in the first 5 months (Lussi \& Francescut, 2003). This in turn implies a drop in the LF values (Lussi et al., 1999) and favors the obtainment of high specificity results. On the other hand, in vitro studies make no mention of the age and origin of the samples. In vivo studies also pose limitations; in effect, in order to ensure total sample validation, these studies are made in third molars or premolars selected for extraction due to surgical or orthodontic indications. The occlusal anatomy in this case differs from that of the permanent first and second premolars, as a result of which the results must be viewed with caution (HeinrichWeltzien et al., 2003). In the case of in vivo studies conducted in permanent first and second 
molars, the teeth presumed to be healthy or with enamel caries cannot be validated due to ethical reasons. The authors must assume the standard, without being able to confirm or discard the presence of caries via fissurotomy. As a result, it is not possible to detect the existence of false-negative readings, which are frequent in the visual inspection-based diagnostic procedure used for sample selection. Two options are available in this situation: elimination of the non-validated teeth, whereby the prevalence will be almost $100 \%$, or assumption of the possible existence of false-negative readings in the gold standard. In both cases, the calculations are not precise, and the results must be examined with caution - as pointed out in the literature (Lussi et al., 2001; Heinrich-Weltzien et al., 2003). Only our in vivo studies (Abalos et al., 2009; 2011; Guerrero, 2011) involve permanent first and second molars with total sample validation, since the category of healthy teeth or teeth with enamel caries could be validated. The molars were to serve as abutments for fixed prostheses, and could be validated via fissurotomy before being worked upon. An alternative for the use of an imperfect reference standard method is mathematical correction of the values of sensitivity and specificity (Brenner, 1996). This adjustment could approximate the performance obtained in the studies to the actual performance of the methods, increasing the external validity of the study. This procedure has been employed by Matos (2011) for the first time in studies of caries detection. Another alternative to in vivo evaluations is the conduction of in vitro studies, but with frozen teeth (Lussi \& Hellwig, 2006), which allows clinical extrapolation of the results. Other limitations in LF studies are represented by plaque or organic material remains, stains, the degree of tooth dehydration, composite fillings or traces of polishing paste - all of which can affect the LF readings, since they are sources of fluorescence and can therefore give rise to false-positive results. In addition, other factors (Abalos \& Jiménez-Planas, 2011) inherent to the tooth such as age, the degree of maturation, and the depth of the pits can influence the measurements obtained (Lundberg et al., 2007).

The variation in LF readings found by our group is considerable (Abalos et al., 2009; 2011), in the same way as in other clinical studies (Anttonen et al., 2003; Lussi et al., 2001). However, the mean values show a gradient through the different categories of lesion extent ( $\mathrm{D}_{0}$ : healthy; $\mathrm{D}_{1+2}$ : enamel caries; $\mathrm{D}_{3+4}$ : dentin caries) that increases as caries progresses (Lussi et al., 2001). This gradient is observed in both in vitro (Baseren \& Gokalp, 2003) and in in vivo studies (Astvaldsdottir et al., 2004; Anttonen et al., 2003; Heinrich-Weltzien et al., 2003; Lussi et al., 2001; Heinrich-Weltzien et al., 2002), and in both permanent teeth (Astvaldsdottir et al., 2004; Heinrich-Weltzien et al., 2003; Lussi et al., 2001; HeinrichWeltzien et al., 2002) and temporary teeth (Anttonen et al., 2003; Lussi \& Francescut, 2003) though the values are lower in the case of the primary dentition. In our investigations (Abalos et al., 2009; 2011) LF was seen to be able to distinguish between enamel caries and dentin caries (Abalos et al., 2009), though without being able to discriminate between healthy teeth and teeth with enamel caries (Abalos et al., 2011). The explanation for this latter observation is that the initial enamel lesion does not induce a significant increase in fluorescence when compared with healthy enamel. Likewise, Lussi in 1999 (Lussi et al., 1999) reported that LF does not seem very adequate for detecting minor changes in the enamel. Some studies (Astvaldsdottir et al., 2004) have reported a weak correlation between the LF readings and the depth of the lesion, though this does not suffice to view LF as a method for determining depth. In other words, while LF appears to be able to establish when lesions invade one tissue or other, it is not useful for discriminating depth within one same tissue, whether enamel or dentin (Lussi et al., 2001; Baseren \& Gokalp, 2003). 
At present, the cutoff values are based on those established by Lussi in 2001 in the context of a clinical study (Lussi et al., 2001), with standardization as follows: 0-13 for healthy teeth, 1420 for enamel caries, and $>20$ for dentin caries. The results of our group are in concordance with these cutoff values (Abalos et al., 2009; 2011), in the same way as in other clinical studies . Our values (Abalos et al., 2011) for healthy first and second molars assessed in vivo range between 0 and 14. Values below 10 in all cases corresponded to healthy fissures. The only previous studies (Bass,eren \& Gokalp, 2003; Sheehy et al., 2001) made to determine the limits in healthy enamel have been conducted in vitro (Bas,eren \& Gokalp, 2003) or in vivo in third molars (Sheehy et al., 2001), with histological validation. Laser fluorescence readings of $>14$ in turn can be indicative of enamel caries, while readings of $\geq 20$ can mean dentin caries, though without necessarily implying operative intervention. As advised by Lussi (Lussi et al., 2001), in patients with low caries risk, fissure aperture should be indicated at LF readings of $\geq 30$.

In contrast to the previously examined techniques, LF is more sensitive than specific, and so implies a greater number of false-positive readings. These readings are normally explained by fluorescence sources unrelated to caries - stained fissures being the main problem facing diagnosis with LF (Angnes et al., 2005; Heinrich-Weltzien et al., 2003) (Fig. 7). The stains contribute an added fluorescence signal that increases the measurement values obtained (Côrtes et al., 2003) by between 5-7 units (Heinrich-Weltzien et al., 2003; Sheehy et al., 2001), and represent a frequent cause of overestimation (Sheehy et al., 2001) and of lessened performance of the test. This must be taken into account in order to adjust or modify the cutoff value. When conducting their studies, investigators must specify the percentage of stained fissures in order to allow improved comparison of the results. In our studies (Abalos et al., 2009; 2011; Guerrero 2011) the percentage was approximately 25\%. Cases of underestimation are rare, and any such situations are attributable to a poor measurement technique and failure to have rotated the instrument tip in all directions.

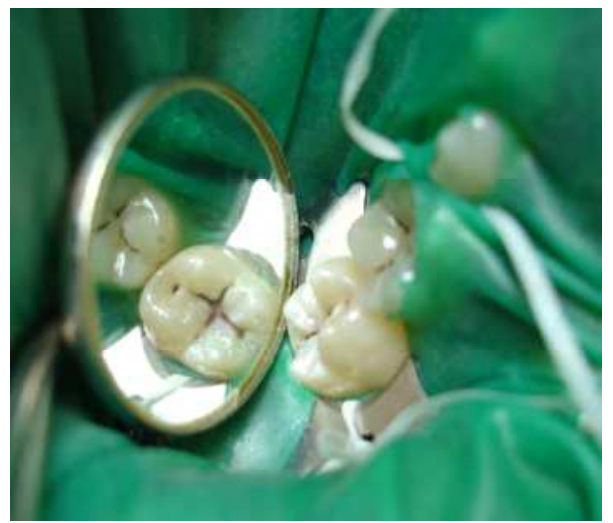

Fig. 7. Stained fissure complicating laser fluorescence (LF) diagnosis.

Receiver operating characteristic (ROC) curves take sensitivity and specificity into account for all the cutoff points, thereby reflecting the global diagnostic capacity of the technique. This analysis also offers the average validity of the method used. Taking Az to represent the area under the ROC curve, $\mathrm{Az}=1$ would represent perfect diagnostic accuracy. In general, a 
value of $\mathrm{Az} \geq 0.80$ is regarded as acceptable, and would mean that the probability of effectively identifying caries is $80 \%$. ROC analysis shows LF to be a good diagnostic technique in application to enamel caries, with $\mathrm{Az}=0.803$ (Abalos et al., 2011). These results are somewhat inferior to those reported by other investigators (Stookey \& GonzalezCabezas, 2001). For dentin caries $\mathrm{Az}=0.85$, reflecting good diagnostic reliability. These findings coincide with those of some in vivo investigations (Heinrich-Weltzien et al., 2003), but exceed the values of 0.64-0.69 described by other in vivo / in vitro studies (Angnes et al., 2005), with histological validation in reference to third molars.

Comparison of the different diagnostic tests can be based on their respective sensitivity and specificity performances, which reflect the comparative reliability of each technique. The NPV value for occlusal dentin caries was $87 \%$, with a PPV value of $79 \%$. The concepts of sensitivity and specificity therefore allow us to assess the validity of a given diagnostic test. Both sensitivity and specificity offer information on the probability of obtaining a concrete result or reading (positive or negative), according to the true condition of the patient in relation to the disease. However, when a patient is subjected to a test, the dentist lacks prior information on the true diagnosis, and the question is actually posed from a reverse perspective: in the event of a positive or negative test result, what is the probability that the patient is actually ill or healthy? Thus, the predictive values complement the information provided by sensitivity and specificity. The results obtained reflect a high NPV and an acceptable PPV. Therefore, LF is a complement to those tests offering high specificity and a high PPV. LF is a coadjuvant to VI, and the use of both techniques combined increases the number of correctly diagnosed lesions.

\subsection{Qualitative light-induced fluorescence (QLF)}

Qualitative light-induced fluorescence (QLF) is used for the detection and quantification of early-stage caries (Pretty, 2006; McComb \& Tam, 2001) and for monitoring demineralization or remineralization of smooth surface lesions (Verdonschot \& van der Veen, 2002; HeinrichWeltzien et al., 2005). The tooth is illuminated by the diffuse blue-green light beam of an argon laser at a wavelength of $488 \mathrm{~nm}$ (Tranæus et al., 2005; McComb \& Tam, 2001). It can also be illuminated by a xenon microdischarge arc lamp and optic fiber system generating blue light at a wavelength of $370 \mathrm{~nm}$ (Pretty, 2006), with conduction by a liquid guide. The images are obtained in a dimmed environment using a portable intraoral video camera, with software processing. These images can be used to calculate lesion size, depth and volume (Tranæus et al., 2005; Zandona \& Zero, 2006). The demineralized areas appear as dark zones, since radiation of the carious lesion is lower than that of the healthy enamel (Tranæus et al., 2005). The intensity of the emitted light is correlated to mineral loss and can be quantified (Verdonschot \& van der Veen, 2002).

QLF is sensitive and reproducible in quantifying smooth surface caries, though it does not discriminate between lesions confined to the enamel layer and dentin caries (McComb \& Tam, 2001). The applicability of this technique appears to be limited by lesion depth (McComb \& Tam, 2001) - QLF being effective up to $400 \mu \mathrm{m}$ in depth, but not beyond. The possibility of adapting the technique to the diagnosis of occlusal caries is under investigation, though few clinical studies have been made to date (Weerheijm et al., 1992; McComb \& Tam, 2001). Table 5 shows the sensitivity and specificity data of in vitro studies on QLF in application to occlusal dentin caries. This diagnostic technique can be affected by 
the degree of humidity or dryness of the fissures, their stains and morphology and does not appear to distinguish between caries and hypoplasia.

\begin{tabular}{|c|c|c|c|c|}
\hline AUTHOR & LEVEL & STUDY & SENSITIVITY & SPECIFICITY \\
\hline Stookey 2001 & Dentin & in vitro & 0.49 & 0.67 \\
\hline Zandona 2006 & Dentin & in vitro & 0.61 & 0.59 \\
\hline Pretty 2004 & Dentin & in vitro & 0.77 & 0.67 \\
\hline McComb 2001 & Dentin & in vitro & $0.72-0.76$ & $0.79-0.81$ \\
\hline
\end{tabular}

Table 5. Sensitivity and specificity of QLF in the diagnosis of hidden dentin caries.

\subsection{Fiber-optic transillumination (FOTI)}

Fiber-optic transillumination (FOTI) (Fig. 8) is a qualitative technique introduced in the 1970s. It is based on light transmission through an optic fiber; as the light falls upon the tooth surface, it spreads through the healthy dental tissue. In this context, caried tissue is characterized by an increased organic component, with alteration of the homogeneity of the inorganic component - thereby resulting in a loss of light transmission capacity.

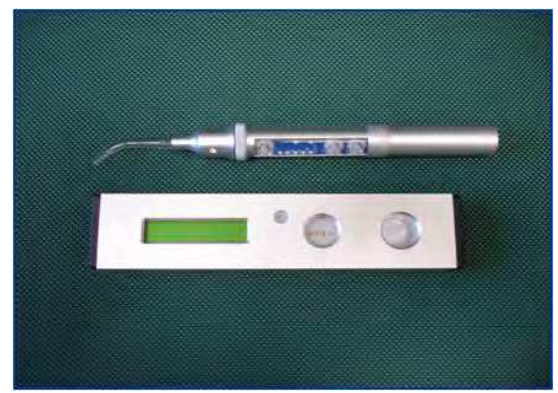

Fig. 8. Fiber-optic transillumination device (DioPower Lamp)

FOTI has been used fundamentally for identifying proximal surface caries (Cortes et al., 2000;), with high specificity and a broader range of sensitivity values (Tranæus et al., 2005). The technique is of great help in diagnosing cracked tooth syndrome (Fig. 9). However, it is little used for diagnosing hidden dentin caries, where moreover few studies have assessed its diagnostic performance, precision and reproducibility.

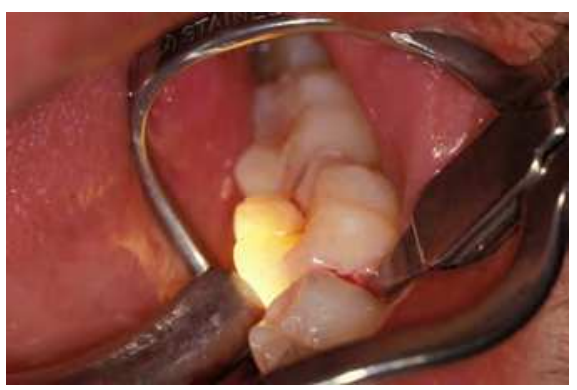

Fig. 9. Cracked tooth syndrome diagnosed by fiber-optic transillumination (FOTI). 
FOTI is more specific than sensitive. Table 6 reports the validity of the test in different in vitro studies referred to occlusal caries. In an in vivo study with full sample validation, our group (Guerrero, 2011) has recorded a sensitivity of 0.47 and a specificity of 1.0. These data are in line with those reported by other in vitro studies (Ashley et al., 1998; Cortes et al., 2000).

\begin{tabular}{|c|c|c|c|c|}
\hline AUTHOR & LEVEL & STUDY & SENSITIVITY & SPECIFICITY \\
\hline Cortes 2000 & enamel & in vitro & $0.74-1$ & $0.23-0.85$ \\
\hline Ashley 1998 & enamel & in vitro & 0.21 & 0.95 \\
\hline Cortes 2000 & dentin & in vitro & 0.74 & 0.85 \\
\hline Ashley 1998 & dentin & in vitro & 0.14 & 0.95 \\
\hline
\end{tabular}

Table 6. Sensitivity and specificity of FOTI in the diagnosis of occlusal non-cavitated caries.

As a coadjutant to visual inspection, FOTI can offer an alternative to X-rays in situations where patient irradiation is not possible. It is therefore interesting to compare both methods. In reference to occlusal caries, some authors (Wenzel et al., 1992) consider transillumination to offer better performance than conventional X-rays in detecting early-stage dentin caries. Cortés (Cortes et al., 2000), in an in vitro study, reported greater sensitivity than specificity for FOTI, and superior performance with respect to X-rays, though in application to the diagnosis of enamel caries. Once caries has progressed to the dentin, FOTI proved to be significantly inferior to conventional X-rays (Guerrero, 2011). Regarding the predictive usefulness of the technique, we recorded a NPV of $54 \%$ and a PPV of $100 \%$, without falsepositive readings (Guerrero, 2011).

However, the fact that FOTI is not routinely used by dental professionals, is not recommended as a technique of choice, and is moreover supported by limited research indicates that the inconveniences which we have observed (Guerrero, 2011) - involving a large proportion of false-negative results - are probably coincident with those of other authors who have studied this technique. The main advantage of FOTI is its optimum PPV performance, which means that any positive reading is almost certainly indicative of an existing lesion.

Digitalization may represent a step forward in transillumination diagnosis. Digital FOTI (DIFOTI) makes use of the digitalized image of a tooth during transillumination, which is analyzed using specific software (Tranæus et al., 2005). The images can be filed, reproduced and studied by different examiners, and may serve to monitor the lesion. Interpretation of the image is where problems are found, however, since the results are not directly quantified by the technique. According to some authors (Pretty \& Maupome, 2004; Pretty, 2006), the caried areas can be detected in their early stages with DIFOTI, appearing as dark areas. The results may be superior to those afforded by radiography (Pretty \& Maupome, 2004; Pretty, 2006), though further studies are needed in order to confirm this possibility.

To summarize, FOTI in combination with visual inspection may be useful for determining occlusal caries depth, though further in vivo studies are needed. While in wait of such studies, we consider that transillumination should not be used for diagnosing hidden dentin caries, due to the low sensitivity of the technique and its poorer results compared with Xrays. However, FOTI in combination with VI should be taken into consideration in those cases where X-rays cannot be obtained. 


\subsection{Electronic caries monitorization (ECM)}

Electronic caries monitorization (ECM) is based on the high electrical conduction resistance of the hard dental tissues. Enamel is a poor electrical conductor though caried enamel shows increased conductance versus intact enamel (Loesche et al., 1979). Demineralized enamel becomes more porous, fills with ion-containing fluid and minerals from saliva, and therefore exhibits increased electrical conductance (McComb \& Tam, 2001).

Two devices have been developed, with tips designed for application to the occlusal surface and for measuring electrical conductance in pits or fissures (Zandona \& Zero, 2006). The Electronic Caries Monitor (LODE, Groningen, the Netherlands), in the same way as its predecessor (Vanguard, Electronic Caries Detector, Massachusetts Manufacturing Cooperation Cambridge, MA, USA), was developed for diagnosing occlusal surface caries, and allows the identification of early-stage demineralization lesions. The sensitivity performance in application to permanent premolars and molars varies from 0.67 to 0.96 , with specificity values of between 0.71 and 0.98 (Tranæus et al., 2005; Pereira et al., 2001; Lussi et al., 1999). The different reviews of ECM describe similar results, with sensitivity values referred to dentin lesions of 0.58 to 0.97 and specificity values between 0.56 and 0.94 . One of the reasons for this range of results may be due to the differences in the way in which the technique is used. The degree of dental tissue hydration may also exert an influence, in the same way as enamel maturation and temperature variations (Tranæus et al., 2005; Pretty, 2006). Table 7 shows the sensitivity and specificity performances recorded from in vitro and in vivo studies with ECM applied to occlusal caries.

\begin{tabular}{|c|c|c|c|c|}
\hline AUTHOR & LEVEL & STUDY & SENSITIVITY & SPECIFICITY \\
\hline Ashley 1998 & enamel & in vitro & 0.65 & 0.73 \\
\hline Ekstrand 1997 & enamel & in vivo & 0.63 & 0.73 \\
\hline Lussi 1999 & dentin & in vitro & $0.58-0.92$ & $0.76-0.94$ \\
\hline
\end{tabular}

Table 7. Sensitivity and specificity of ECM in the diagnosis of occlusal non-cavitated caries.

\subsection{Conclusions of the diagnostic tests}

Modern dental practice needs diagnostic methods to diagnose caries in the early stages of the disease, and research efforts must focus on satisfying this need. The traditional diagnostic techniques offer high specificity, but with the possibility of false-negative results due to dentin caries. Laser fluorescence (LF) shows high sensitivity, and is able to identify hidden dentin caries in situations where visual inspection (VI) and X-rays are unable to detect the lesions. However, because of its lesser specificity and the low current prevalence of caries in the industrialized world, LF should be used as a coadjutant to VI in diagnosing hidden dentin caries. It has been estimated that an additional 30-50\% of noncavitated occlusal caries can be detected in the early stages with LF. Bitewing X-rays represent a complement to VI, but is only able to detect the lesion once it has advanced in the dentinal tissue. As a result, different studies (Anttonen et al., 2003; Ricketts et al., 1997) consider LF to be more effective than bitewing X-rays as an adjunct to VI in diagnosing occlusal caries.

Based on the results obtained, the combination of LF and VI appears as an interesting option. In effect, the two techniques complement each other, securing superior overall 
performance, since one (LF) is more sensitive than specific, while the other (VI) is more specific than sensitive. When interpreting the results of diagnostic tests, a negative diagnostic result is sometimes more valuable than a positive diagnostic reading. This can be explained as follows: although clinicians seek values from which caries can be diagnosed, the opposite sometimes apply. In effect, we have observed that LF readings of under 10 will never indicate an actual caried tooth, and LF readings of under 20 in stained fissures or cracks will never indicate or correspond to dentin caries. Thus, a first conclusion could be that in the case of a doubtful VI result with LF values of under 10 involving adequate instrument tip rotation, we must assume that the tissue is healthy, in the same way that LF readings of under 20 in stained fissures do not correspond to dentin caries. LF readings of 10-20 with normal VI findings are indicative of healthy tissue, particularly in the presence of some fissure staining. However, in the differential diagnosis between healthy tissue and enamel caries $\left(\mathrm{D}_{0}-\mathrm{D}_{1}\right)$, over-estimation of the lesion is not particularly important, since the treatment involved is of a preventive nature. LF is a help in VI, particularly when the findings of the latter are not clear and a diagnosis cannot be established. LF moreover acquires an added diagnostic value when its readings are low in stained fissures or high in unstained fissures. All teeth with readings above 14 must be subjected to preventive measures and monitorization or control. In turn, LF readings of over 20 can imply that the lesion has reached the dentin, though the experience of the operator and the patient risk factors must always be taken into account. The most important conclusions of this Chapter, based on our investigations (Abalos et al., 2009; 2011; Guerrero, 2011), can be listed as follows:

1. Visual inspection, with or without magnification, is the method of choice for diagnosing non-cavitated caries. For adequate diagnostic performance, use must be made of the Ekstrand criteria, combining VI with other techniques such as LF. Visual inspection is more specific than sensitive, and so a positive diagnosis requires fissure aperture, while a negative diagnostic interpretation is inconclusive and required periodic revisions.

2. Conventional or digital X-rays constitute a necessary complementary technique. Its high specificity means that in the case of a positive diagnosis, fissure aperture should be carried out, and it can be used to assess the extent of the lesion. X-rays are not useful for the diagnosis of very early stage lesions.

3. Laser fluorescence is a useful technique that serves as an adjunct or complement to visual inspection, offering high sensitivity and acceptable specificity. LF readings of under 10 are indicative of a healthy tooth, while readings of over 20 may indicate dentin invasion - though the definitive interpretation must be made in combination with visual inspection. In turn, readings of 10-20 indicate that lesion monitorization is required. LF is unable to establish the depth of the lesion within the tissue (either enamel or dentin). Low readings in stained fissures rule out dentin caries.

4. Probe exploration is not recommended for diagnosing non-cavitated caries. Fiber-optic transillumination (FOTI) is not a method of choice, since it is scantly sensitive - though it may serve as a complementary technique when X-rays cannot be obtained.

5. The combination of exploratory techniques, together with technical and scientific knowledge, are essential for establishing a correct diagnosis of non-cavitated caries. The individual patient factors must be taken into account in order to indicate fissure aperture or periodic revisions or controls. 


\section{Intervention protocol}

Based on the results obtained, and in the context of the diagnostic techniques that are accessible to dental surgeons, we recommend the following protocol:

$\rightarrow$ Positive X-ray or FOTI findings..................... Dentin caries

$\rightarrow$ Visual inspection (better under magnification):

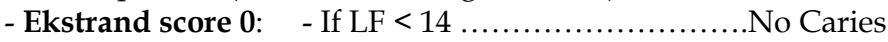

- If LF 15-20 ..................... Monitorization enamel

*Stained fissure............. No caries

- If LF > 20 ........................Monitorization dentin

$\rightarrow$ Visual inspection (better under magnification):

- Ekstrand score 1-2: - If LF $<10$ No Caries

- If LF 10-20 Enamel caries

- If LF > 20 Monitorization dentin

*Stained fissure Monitorization enamel

$\rightarrow$ Visual inspection (better under magnification):

- Ekstrand score 3-4: - If LF < 20 $2^{\text {nd }}$ measure rotating tip

*2nd LF $<20$ Enamel caries

- If LF > 20 Dentin caries

*Stained fissure .Fissure aperture

\section{Treatment}

The present Chapter focuses on techniques applicable to the diagnosis of hidden dentin caries. However, as a complement to the measures recommended in the above intervention protocol, we will outline the therapeutic approach applicable to each diagnosis.

\subsection{Fissure aperture}

Fissure aperture applies when we believe but cannot fully confirm that dentin caries exists. A fissurotomy drill is used to open the fissure, crack or pit until reaching the dentin. A finetipped probe is then used to check dentin hardness, and if there are no carious lesions, crack sealant is applied. In contrast, if caries is identified, the lesion is eliminated, followed by filling with composite resin or silver amalgam.

\subsection{Enamel monitorization}

In this case the doubt is whether enamel caries exists or not. Bacterial plaque control is indicated in these situations, based on oral and dental hygiene measures and topical fluor application. If the suspicion of caries results from high LF readings with normal VI findings, monitorization fundamentally should be carried out with LF. The detection of positive VI signs or increased LF readings during follow-up, potentially indicative of lesion progression, requires fissure aperture.

If caries is suspected on the basis of the VI findings, with normal LF results, the subsequent controls should be centered on VI. The detection of an increase in positive VI signs or 
increased LF readings during follow-up, potentially indicative of dentin involvement, requires fissure aperture.

\subsection{Enamel caries}

Treatment should distinguish between active and inactive lesions, since such a distinction is important in management terms. The development of techniques for differentiating between active and inactive lesions is thus seen as a necessity, since very few studies in this field have been published to date (Bader \& Shugars, 2004). The general clinician experiences great difficulty in distinguishing between these lesions (Ekstrand et al., 2005). When the band and plaque are removed, the clinical features of the active lesion have been recorded as a dull/opaque white area, which is said to be rough when a probe is moved across the surface. Accordingly, the signs for establishing a differentiation are: a) Whether the lesion was dull/matt or shiny/glossy; and b) The tactile sensation of the lesion to a ball-ended probe run gently across the surface was recorded as smooth or rough to the probe.

According to some studies (Pretty, 2006), laser fluorescence is able to establish differences between the readings corresponding to active and inactive enamel caries in permanent molars. In this sense, LF would be able to serve in monitoring the lesion. However, other studies (Toraman et al., 2008) consider that the technique does not register the changes that occur during remineralization and caries development arrest, and cannot serve for monitorization purposes.

Following improved oral hygiene, the lesion is no longer active, and there may be remineralization within the lesion and abrasion of the eroded surface enamel during oral hygiene procedures and normal function. This leads to a surface which feels smooth when a probe is gently run across it, and which appears shinier (Thylstrup et al., 1994). Once inactive, monitoring of the lesion should continue. Persistent activity is indicative of the need for fissure aperture and the placement of crack sealant.

\subsection{Dentin monitorization}

Laser fluorescence readings of under 20 in the presence of positive visual inspection findings are suggestive of dentin caries. Fissure aperture would be indicated with LF readings of over 20 .

\subsection{Dentin caries}

Enamel aperture with a diamond drill, followed by elimination of the caried dentin with adequate instruments, is indicated in the case of dentin caries. Filling with resin composites or silver amalgam should follow. Ceramic incrustations may be considered in the case of important tooth involvement.

Both the described intervention protocol and the specified treatments cannot encompass all the possible clinical situations. Likewise, they cannot replace clinician experience and the global vision afforded by all the diagnostic techniques, the tooth and oral conditions, and even the individual conditions of each patient. However, the information provided may serve to establish bases and guidelines for intervention and recommendations fundamented on experience and research. 


\section{References}

Abalos, C. Herrera, M. Jimenez-Planas, A. Llamas, R. (2009). Performance of laser fluorescence for detection of occlusal dentinal caries lesions in permanent molars: an in vivo study with total validation of the sample. Caries Res, Vol.43, No.2, PP.137-141, ISSN 0008-6568.

Abalos, C. Jiménez-Planas, A. (2011) La Láser-Fluorescencia en el diagnóstico temprano de la caries no cavitada. Dentum, Vol.11, No.1, pp.20-23, ISNN 1575-6157.

Abalos, C. Mendoza, A. Jiménez-Planas, A. Guerrero, A. Chaparro, A. García-Godoy, F. (2012) Clinical detection of enamel caries by laser fluorescence. Am J Dent, (In press), ISSN 0894-8275.

Angnes, V. Angnes, G. Batisttella, M. Grande, RH. Loguercio, AD. Reis, A. (2005) Clinical effectiveness of laser fluorescence, visual inspection and radiography in the detection of occlusal caries. Caries Res, Vol.39, No.6, pp.490-495, ISSN 0008-6568.

Anttonen, V. Seppa, L. Hausen, H. (2003) Clinical study of the use of the laser fluorescence device DIAGNOdent for detection of occlusal caries in children. Caries Res, Vol.37, No.1, pp.17-23, ISSN 0008-6568.

Ashley, PF. Blinkhorn, AS. Davies, RM. (1998). Occlusal caries diagnosis: an in vitro histological validation of the Electronic Caries Monitor (ECM) and other methods. J Dent, Vol.26, No.2, pp.83-88, ISSN 0300-5712.

Astvaldsdottir, A. Holbrook, WP. Tranaeus, S. (2004). Consistency of Diagnodent instruments for clinical assement of fissure caries. Act Odon Scand, Vol.62, No.4, pp.193-198, ISSN 0001-6357.

Bader, JD. Shugars, DA. Bonito, AJ. (2002). A systematic review of the performance of methods for identifying carious lesions. J Public Health Dent, Vol.62, No.4, pp201213, ISSN 0022-4006.

Bader. JD, Shugars, DA. (2004). A systematic review of the performance of a laser fluorescence device for detecting caries. J Am Dent Assoc, Vol.135, No.10, pp.14131426, ISSN 0002-8177.

Bagramian, RA. Garcia-Godoy, F. Volpe, AR. (2009). The global increase in dental caries. A pending public health crisis. Am J Dent, Vol.22, pp.3-8, ISSN 0894-8275.

Bamzahim, M. Shi, X-. Angmar-Mainsson, B. (2002). Occlusal caries detection and quantification by DIAGNOdent and Electronic Caries Monitor: In vitro comparison. Acta Odontologica Scandinavica, Vol.60, No.6, pp.360-364, ISSN 00016357.

Bașeren, NM. Gokalp, S. (2003). Validity of a laser fluorescence system (DIAGNOdent) for detection of occlusal caries in third molars: An in vitro study. Journal of Oral Rehabilitation, Vol.30, No.12, pp.1190-1194, ISSN 0305-182X.

Bonilla, V. (1998). Estudio comparativo del diagnóstico "in vivo" de la caries de superficie proximal con radiografía convencional y laservisiografía en 145 dientes del sector posterior. Ph.Thesis, University of Seville.

Brännstrom, M. Gola, G. Nordenvall, Kj. Torstenson, B. (1980). Invasion of microorganisms and some structural changes in incipient enamel caries. Caries Res, Vol.14, pp.27684, ISSN 0008-6568.

Brenner, H. (1996). Correcting for exposure misclassification using an alloyed gold standard. Epidemiology, Vol.7, pp.406-410, ISNN 1044-3983. 
Cortes, DF. Ekstrand, KR. Elias-Boneta, AR. Ellwood, RP. (2000). An in vitro comparison of the ability of fibre-optic transillumination, visual inspection and radiographs to detect occlusal caries and evaluate lesion depth. Caries Res, Vol.34, No.6, pp.443447, ISSN 0008-6568.

Costa, AM. Paula, LM. Bezerra, AC. (2008). Use of Diagnodent for diagnosis of noncavitated occlusal dentin caries. J Appl Oral Sci, Vol.16, No.1, pp.18-23, ISSN 16787757.

Ekstrand, KR. Kuzmina, I. Bjorndal, L. Thylstrup, A. (1995). Relationship between external and histologic features of progressive stages of caries in the occlusal fossa. Caries Res, Vol.29, No.4, pp.243-250, ISSN 0008-6568.

Ekstrand, KR. Ricketts, DN. Kidd, EA. (1997). Reproducibility and accuracy of three methods for assessment of demineralization depth of the occlusal surface: an in vitro examination. Caries Res, Vol.31, No.3, pp.224-231, ISSN 0008-6568.

Ekstrand, KR. Ricketts, DN. Kidd, EA. Qvist, V. Schou, S. (1998). Detection, diagnosing, monitoring and logical treatment of occlusal caries in relation to lesion activity and severity: an in vivo examination with histological validation. Caries Res, Vol.32, No.4, pp.247-254, ISSN 0008-6568.

Ekstrand, KR. Ricketts, DN. Longbottom, C. Pitts, NB. (2005). Visual and tactile assessment of arrested initial enamel carious lesions: an in vivo pilot study. Caries Res, Vol.39, No.3, pp.173-177, ISSN 0008-6568.

Farah, RA. Drummond, BK. Swain, MV. (2008). Williams S. Relationship between laser fluorescence and enamel hypomineralisation. J Dent, Vol.36, No.11, pp.915-921, ISSN 0300-5712.

Forgie, AH. Pine, CM. Pitts, NB. (2002). The use of magnification in a preventive approach to caries detection. Quintessence Int, Vol.33, No.1, pp.13-16, ISSN 0033-6572.

Francescut, P. Zimmerli, B. Lussi, A. (2006). Influence of different storage methods on laser fluorescence values: A two-year study. Caries Research, Vol.40, No.3, pp.181-185, ISSN 0008-6568.

Guerrero, E. (2011). Validez y seguridad de las pruebas diagnósticas para la caries oculta de dentina: un estudio in vivo. Ph Thesis. University of Seville.

Hamilton, JC. (2005). Should a dental explorer be used to probe suspected carious lesions? Yes--an explorer is a time-tested tool for caries detection. J Am Dent Assoc, Vol.136, No.11, pp.1526-1530, ISSN 0002-8177.

Heinrich-Weltzien, R. Weerheijm, KL. Kuihnisch, J. Oehme, T. Stösser, L. (2002). Clinical evaluation of visual, radiographic, and laser fluorescence methods for detection of occlusal caries. Journal of Dentistry for Children, Vol.69, No.2, pp.127-132, ISSN 00220353.

Heinrich-Weltzien, R. Kuhnisch, J. Oehme, T. Ziehe, A. Stosser, L. Garcia-Godoy, F. (2003). ( Comparison of different DIAGNOdent cut-off limits for in vivo detection of occlusal caries. Oper Dent, Vol,28, No.6, pp. 672-680, ISSN 0361-7734.

Heinrich-Weltzien, R. Kuhnisch, J. Ifland, S. Tranaeus, S. Angmar-Mansson, B. Stosser, L. (2005). Detection of initial caries lesions on smooth surfaces by quantitative lightinduced fluorescence and visual examination: an in vivo comparison. Eur J Oral Sci, Vol.113, No.6, pp.494-498, ISSN 0909-8836.

Hibst, R. Paulus, R. (1999). Caries detection by red excited fluorescence: investigations on fluorophores. Caries Res, Vol.33, pp.295, ISSN 0008-6568. 
Hibst, R. Paulus, R. Lussi, A. (2001). Detection of occlusal caries by laser fluorescence: Basic and clinical investigations. Medical Laser Application, Vol.16, No.3, pp.205-213, ISSN $1615-1615$.

Huysmans, MC. Longbottom, C. Pitts, N. (1998). Electrical methods in occlusal caries diagnosis: An in vitro comparison with visual inspection and bite-wing radiography. Caries Res, Vol.32, No.5, pp.324-329, ISSN 0008-6568.

Hyat, Tp. (1923). Prophylactic odontotomy : the cutting into the tooth for prevention of disease. Dental cosmos, Vol.65, pp.234-241, ISSN 0096-0187.

Kidd, EA. Ricketts, DN. Pitts, NB. (1993). Occlusal caries diagnosis: a changing challenge for clinicians and epidemiologists. J Dent, Vol.21, No.6, pp.323-331, ISSN 0300-5712.

Kidd, EA. Ricketts, DN. Beighton, D. (1996). Criteria for caries removal at the enameldentine junction: a clinical and microbiological study. Br Dent J, Vol.180, No.8, pp.287-291, ISNN 0007-0610.

Kuhnisch, J. Goddon I. Berger, S. Senkel, H. Bucher, K. Oehme, T. et al. (2009). Development, methodology and potential of the new Universal Visual Scoring System (UniViSS) for caries detection and diagnosis. Int J Environ Res Public Health, Vol.6, No.9, pp.2500-2509, ISNN 0960-3123.

Landis, JR. Koch, GG. (1977). The measurement of observer agreement for categorical data. Biometrics, Vol.33, No.1, pp.159-174, ISSN 0006-341X.

Llamas, R. Bonilla, V. Sánchez-Barriga, R. Pastor, C. Herrera, M. (2000). La caries, una enfermedad actual (II). Características morfológicas de la caries de esmalte no cavitada. Rev Eur Odontoestomatol, Vol.3, pp.129-40, ISSN 0214-8668.

Loesche, WJ. Svanberg, ML. Pape, HR. (1979). Intraoral transmission of Streptococcus mutans by a dental explorer. J Dent Res, Vol.58, No.8, pp.1765-1770, ISSN 00220345 .

Lundberg, P. Morhed-Hultvall, ML. (2007). Twetman S. Mutans streptococci colonization and longitudinal caries detection with laser fluorescence in fissures of newly erupted 1st permanent molars. Acta Odontol Scand, Vol.65, No.4, pp.189-193, ISSN 0001-6357.

Lussi, A. (1991). Validity of diagnostic and treatment decisions of fissure caries. Caries Res, Vol.25, No.4, pp.296-303, ISSN 0008-6568.

Lussi A. (1993). Comparison of different methods for the diagnosis of fissure caries without cavitation. Caries Res, Vol.27, No.5, pp.409-416, ISSN 0008-6568.

Lussi, A. Imwinkelried, S. Pitts, NB. Longbottom, C. Reich, E. (1999). Performance and Reproducibility of a Laser Fluorescence System for Detection of Occlusal Caries in vitro. Caries Research, Vol.33, No.4, pp.261-266, ISSN 0008-6568.

Lussi, A. Megert, B. Longbottom, C. Reich, E. Francescut, P. (2001). Clinical performance of a laser fluorescence device for detection of occlusal caries lesions. European Journal of Oral Sciences, Vol.109, No.1, pp.14-19, ISSN 0909-8836.

Lussi, A. Megert, B. Longbottom, C. Reich, E. Francescut, P. (2001). Laser fluorescence may increase diagnostic sensitivity in detecting class I caries. Journal of Evidence-Based Dental Practice, Vol.1, No.2, pp.95-96, ISSN 1532-3382.

Lussi, A. Francescut, P. ( 2003). Performance of conventional and new methods for the detection of occlusal caries in deciduous teeth. Caries Research, Vol.37, No.1, pp.2-7, ISSN 0008-6568. 
Lussi, A. Hellwig, E. (2006). Performance of a new laser fluorescence device for the detection of occlusal caries in vitro. Journal of Dentistry, Vol.34, No.7, pp.467-471, ISSN 03005712.

Matos, R. Novaes, TF. Braga, MM. Siqueira, WL. Duarte, DA. Mendes, FM. (2011). Clinical Performance of Two Fluorescence-Based Methods in Detecting Occlusal Caries Lesions in Primary Teeth Caries Res, Vol.45, pp.294-302, ISSN 0008-6568.

McComb, D. Tam, LE. (2001). Diagnosis of occlusal caries: Part I. Conventional methods. Journal Canadian Dental Association, Vol.67, No.8, pp.454-457, ISSN 0008-3372.

Mejare, I. Kallestal, C. Stenlund, H. Johansson, H. (1998). Caries development from 11 to 22 years of age: a prospective radiographic study. Prevalence and distribution. Caries Res, Vol.32, No.1, pp.10-16, ISSN 0008-6568.

Mejàre, I. Stenlund, H. Zelezny-Holmlund, C. (2004) Caries incidence and lesion progression from adolescence to young adulthood: A prospective 15-year cohort study in Sweden. Caries Res, Vol. 38, pp.130-41, ISSN 0008-6568.

Mendes, FM. de Oliveira, E. de Faria, DL. Nicolau, J. (2006). Ability of laser fluorescence device associated with fluorescent dyes in detecting and quantifying early smooth surface caries lesions. J Biomed Op, Vol.11, No.2, pp.024007, ISNN 1083-3668.

Ngaotheppitak, P. Darling, CL. Fried, D. (2005). Measurement of the severity of natural smooth surface (interproximal) caries lesions with polarization sensitive optical coherence tomography. Lasers Surg Med, Vol.37, No.1, pp.78-88, ISSN 0196-8092.

Nyvad, B. Machiulskiene, V. Baelum, V. (1999). Reliability of a new caries diagnostic system differentiating between active and inactive caries lesions. Caries Res, Vol.33, No.4, pp.252-260, ISSN 0008-6568.

Pastor, C. Lopez, G. Gomez, I. Sanchez-Barriga, R. Llamas, R. (1998). Valoración de los métodos de exploración de caries oclusales sin cavitación. Rev Eur Odontoestomatol, Vol.4, pp213-24, ISSN 0214-8668

Pereira, AC. Verdonschot, EH. Huysmans, MC. (2001). Caries detection methods: can they aid decision making for invasive sealant treatment? Caries Res, Vol.35, No.2, pp.8389, ISSN 0008-6568.

Pitts, N. (2004). "ICDAS"--an international system for caries detection and assessment being developed to facilitate caries epidemiology, research and appropriate clinical management. Community Dent Health, Vol.21, 3, pp.193-198, ISSN 0265-539X.

Pitts, NB. Stamm, JW. (2004). International Consensus Workshop on Caries Clinical Trials (ICW-CCT)--final consensus statements: agreeing where the evidence leads. J Dent Res, Vol.83 Spec, No.C:C125-8, ISSN 0022-0345.

Pretty, IA. Maupome, G. (2004). A closer look at diagnosisi in clinical dental practice. Part 5. Emerging technologies for caries detection and diagnosis. Journal Canadian Dental Association, Vol.70, No.8, pp.540, ISSN 0709-8936.

Pretty, IA. (2006). Caries detection and diagnosis: novel technologies. J Dent, Vol.34, No.10, pp. 727-739, ISSN 0300-5712.

Reis, A. Mendes, FM. Angnes, V. Angnes, G. Grande, RH. Loguercio, AD. (2006). Performance of methods of occlusal caries detection in permanent teeth under clinical and laboratory conditions. J Dent, Vol.34, No.2, pp89-96, ISSN 0300-5712.

Ricketts, DN. Whaites, EJ. Kidd, EA. Brown, JE. Wilson, RF. (1997). An evaluation of the diagnostic yield from bitewing radiographs of small approximal and occlusal 
carious lesions in a low prevalence sample in vitro using different film types and speeds. Br Dent J, Vol.182, No.2, pp.51-58, ISSN 0007-0610.

Sheehy, EC. Brailsford, SR. Kidd, EAM. Beighton, D. Zoitopoulos, L. (2001). Comparison between Visual Examination and a Laser Fluorescence System for in vivo Diagnosis of Occlusal Caries. Caries Research, Vol.35, No.6, pp.421-426, ISSN 0008-6568.

Stookey, GK. Gonzalez-Cabezas, C. (2001). Emerging methods of caries diagnosis. J Dent Educ, Vol.65, No.10, pp.1001-1006, ISSN 0022-0337.

Thylstrup, A. Bruun, C. Holmen, L. (1994). In vivo caries models--mechanisms for caries initiation and arrestment. Adv Dent Res, Vol.8, No.2, pp.144-157, ISSN 0895-9374.

Toraman, M. Peker, I. Deniz, H. Bala, O. Altunkaynak, B. (2008). In vivo comparison of laser fluorescence measurements with conventional methods for occlusal caries detection. Lasers Med Sci, Vol.23, No.3, pp.307-312, ISNN 0268-8921.

Tranæus, S. Shi, X-. Angmar-Mainsson, B. (2005). Caries risk assessment: Methods available to clinicians for caries detection. Community Dentistry and Oral Epidemiology, Vol.33, No.4, pp.265-273, ISSN 0301-5661.

Verdonschot, EH. van der Veen, MH. (2002), Lasers in dentistry 2. Diagnosis of dental caries with lasers. Nederlands Tijdschrift voor Tandheelkunde, Vol.109, No.4, pp.122-126, ISSN 0028-2200.

Weerheijm, KL. Gruythuysen, RJ. van Amerongen, WE. (1992). Prevalence of hidden caries. ASDC J Dent Child, Vol.59, No.6, pp.408-412, ISNN 0022-0353

Weerheijm, KL. Groen, HJ. Bast, AJ. Kieft, JA. Eijkman, MA. van Amerongen, WE. (1992). Clinically undetected occlusal dentine caries: a radiographic comparison. Caries Res, Vol.26, No.4, pp.305-309, ISSN 0008-6568.

Wenzel, A. Fejerskov, O. Kidd, E. Joyston-Bechal, S. Groeneveld, A. (1990). Depth of occlusal caries assessed clinically, by conventional film radiographs, and by digitized, processed radiographs. Caries Res, Vol.24, No.5, pp.327-333, ISSN 0008-6568.

Wenzel, A. Larsen, MJ. Fejerskov, O. (1991). Detection of occlusal caries without cavitation by visual inspection, film radiographs, xeroradiographs, and digitized radiographs. Caries Res, Vol.25, No.5, pp.365-371, ISSN 0008-6568.

Wenzel, A. Verdonschot, EH. Truin, GJ. Konig, KG. (1992). Accuracy of visual inspection, fiber-optic transillumination, and various radiographic image modalities for the detection of occlusal caries in extracted non-cavitated teeth. J Dent Res, Vol.71, No.12, pp.1934-1937, ISSN 0022-0345.

Wenzel, A. (1998). Digital radiography and caries diagnosis. Dentomaxillofac Radiol, Vol.27, No.1, pp.3-11, ISSN 0250-832X.

Wolwacz, VF. Chapper, A. Busato, AL. Barbosa, AN. (2004). Correlation between visual and radiographic examinations of non-cavitated occlusal caries lesions -- an in vivo study. Braz Oral Res, Vol.18, No.2, pp.145-149, ISSN 1806-8324.

Zandona, AF. Zero, DT. (2006). Diagnostic tools for early caries detection. J Am Dent Assoc, Vol.137, No.12, pp.1675-1684, ISSN 0002-8177. 


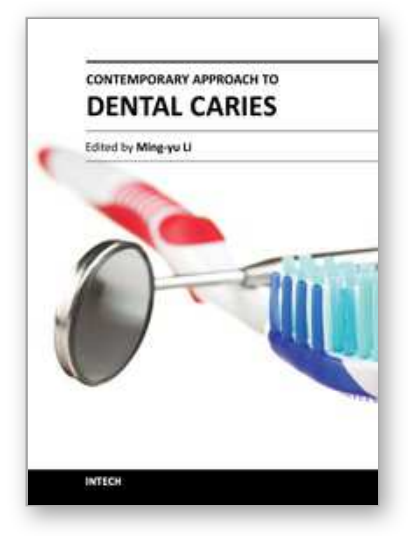

\author{
Contemporary Approach to Dental Caries \\ Edited by Dr. Ming-Yu Li
}

ISBN 978-953-51-0305-9

Hard cover, 488 pages

Publisher InTech

Published online 14, March, 2012

Published in print edition March, 2012

With an update of the recent progress in etiology, pathogenesis, diagnosis, and treatment of caries, it may be said that the final defeat of dental caries is becoming possible soon. Based on the research in this area in recent decades, "Contemporary Approach to Dental Caries" contained the caries in general, the diagnosis of caries, caries control and prevention, the medical treatment of caries, dental caries in children and others such as secondary caries. This book provides the reader with a guide of progress on the study of dental caries. The book will appeal to dental students, educators, hygienists, therapists and dentists who wish to update their knowledge. It will make you feel reading is profitable and useful for your practice.

\title{
How to reference
}

In order to correctly reference this scholarly work, feel free to copy and paste the following:

Camilo Abalos, Amparo Jiménez-Planas, Elena Guerrero, Manuela Herrera and Rafael Llamas (2012). How to Diagnose Hidden Caries? The Role of Laser Fluorescence, Contemporary Approach to Dental Caries, Dr. Ming-Yu Li (Ed.), ISBN: 978-953-51-0305-9, InTech, Available from:

http://www.intechopen.com/books/contemporary-approach-to-dental-caries/how-to-diagnose-hidden-cariesthe-role-of-laser-fluorescence

\section{INTECH}

open science | open minds

\section{InTech Europe}

University Campus STeP Ri

Slavka Krautzeka 83/A

51000 Rijeka, Croatia

Phone: +385 (51) 770447

Fax: +385 (51) 686166

www.intechopen.com

\section{InTech China}

Unit 405, Office Block, Hotel Equatorial Shanghai

No.65, Yan An Road (West), Shanghai, 200040, China

中国上海市延安西路65号上海国际贵都大饭店办公楼 405 单元

Phone: +86-21-62489820

Fax: +86-21-62489821 
(C) 2012 The Author(s). Licensee IntechOpen. This is an open access article distributed under the terms of the Creative Commons Attribution 3.0 License, which permits unrestricted use, distribution, and reproduction in any medium, provided the original work is properly cited. 